\title{
Policy lens to focus integration of home care under development
}

I $\mathrm{n}$ a bid to reduce confusion and disparities in the planning of home care policies across the country, the Canadian Home Care Association (CHCA) is drafting a national framework to outline the role of home care within the health care system.

The tool, dubbed the "Home Care Policy Lens," will help authorities "develop and evaluate integrated care policies and identify issues that impact performance and responsiveness of the home and continuing care sector" (www.hc-sc.gc.ca/ahc-asc/media/nr-cp /_2012/2012-10-eng.php). It's hoped the lens will help policy-makers "to assess requirements for issues such as human resource needs and the optimal role for home care within integrated health care delivery models" (www.hc-sc .gc.ca/ahc-asc/media/nr-cp/_2012/2012 -10bk-eng.php).

CHCA Executive Director Nadine Henningsen says "we know there are already some really great models [for integrated home care delivery] out there and as opposed to describing them, we want to peel back the onion to say what are some of the critical elements that make those models work really well so we'll be able to share those right across the country. ... What we're hoping to do is not necessarily prescribe to jurisdictions how to do it but give them [a checklist of] common challenges or common issues that, no matter where you are in the country, need to be considered."

As part of the initiative, CHCA will:

- "complete a literature review of home care issues within integrated care models;

- draft the Home Care Policy Lens which will contain relevant information, questionnaires, and checklists;

- host three national forums to obtain stakeholder input into the draft home care policy tool and seek feedback on its application;

- complete pilot testing of the tool in

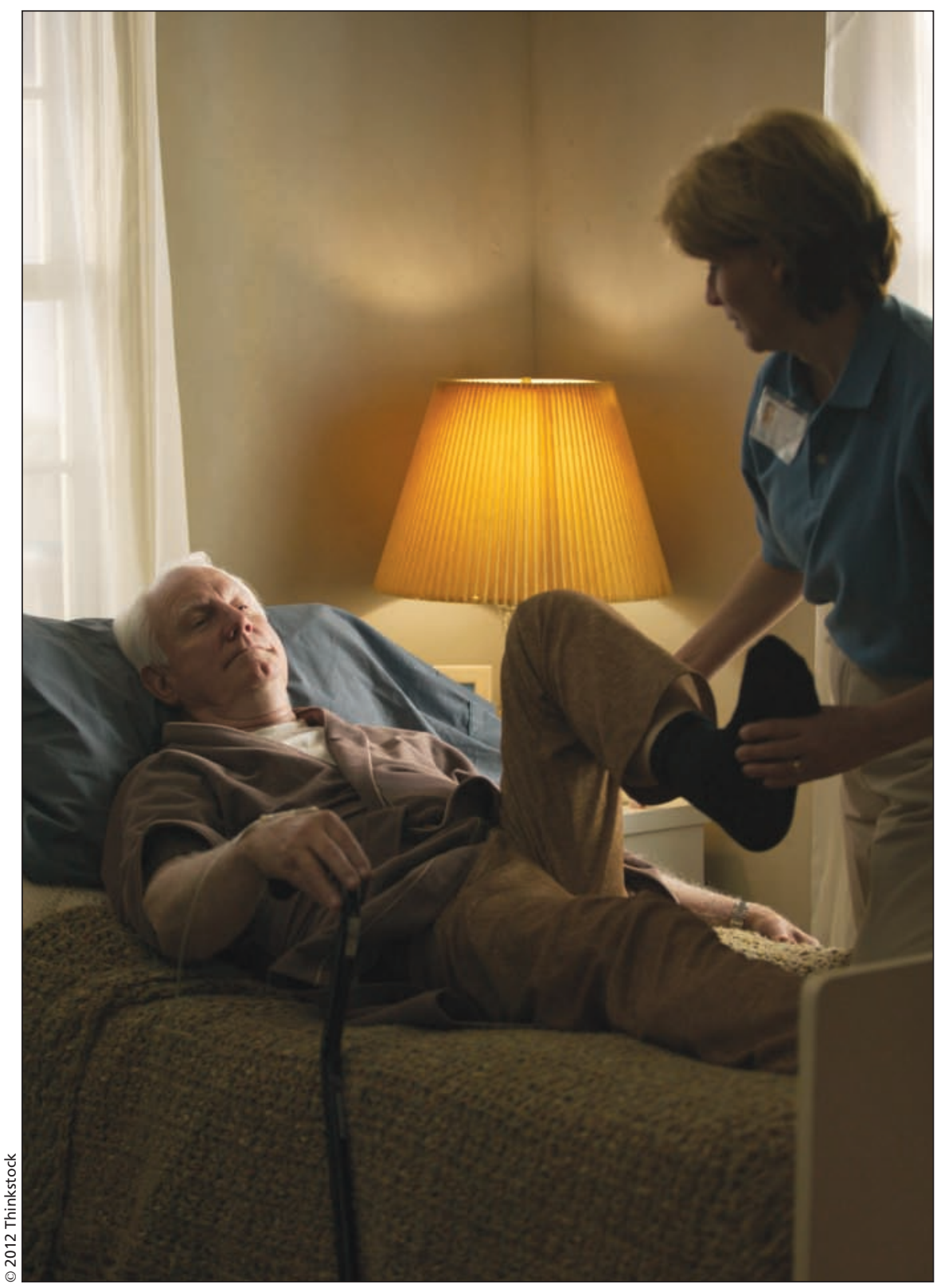

It's projected by the Canadian Home Care Association that roughly 1.5 million Canadians receive home care services annually.

several regions across the country; and

- evaluate the tool based on the forum, pilot testing, and other input from the health care policy and servicedelivery community."

One million Canadians currently receive publicly funded home care services annually, while another 500000 individuals access services not funded by the government, according to a CHCA report, Access to Quality Health Care The Home Care Contribution (www .cdnhomecare.ca/media.php?mid=2844). 
The lens should help governments and home care providers develop integrated services, Bernadine Gibson, a home care consultant for the Saskatchewan Ministry of Health's community care branch, writes in a statement. Although "it is recognized that an integrated and seamless system of care makes sense, it is also a challenge for many systems and providers to develop and implement successful integration models. Becoming an integrated system of managing clientele and services requires a change in the processes, as well as a new way of thinking, collaborating, and providing service."

Health Canada, which provided a $\$ 151$ 200/two-year grant for the exercise, anticipates the lens will build awareness of common challenges across jurisdictions, including "determining the most appropriate role and adequate resources for the home and continuing care sector," Leslie Meerburg, media relations officer for the department, writes in an email.

Henningsen says confusion over roles and responsibilities within an integrated system is "one of the major gaps we see right across the country, whether we're integrating home care with acute care or primary health care or long term care."

For example, "when we first started working with the home care groups and the family health teams, what we initially found is that the family health teams didn't understand the scope and capabilities [of] home care. ... So because they didn't have that understanding or the communication channels there, they either had unrealistic expectations or they didn't know what they could expect from each other."

Such role confusion can result in difficulties allocating resources, whether human, technical or financial, she adds. The lens could help identify where the logjams are occurring and "open a lot of dialogue and communication that may not have happened otherwise."

CHCA will release the new policy lens in October at the 2012 Home Care Summit in Vancouver, British Columbia. — Lauren Vogel, CMAJ

CMAJ 2012. DOI:10.1503/cmaj.109-4110 